\title{
Postoperative Clipping Status after a Pterional versus Interhemispheric Approach for High-Positioned Anterior Communicating Artery Aneurysms
}

\author{
Myungsoo Kim, Byoung-Joon Kim, Wonsoo Son, Jaechan Park \\ Department of Neurosurgery, School of Medicine, Kyungpook National University, Daegu, Korea
}

Objective : When treating high-positioned anterior communicating artery (ACoA) aneurysms, pterional-transsylvian and interhemispheric approaches are both viable options, yet comparative studies of these two surgical approaches are rare. Accordingly, this retrospective study investigated the surgical results of both approaches.

Methods : Twenty-four patients underwent a pterional approach $(n=11)$ or interhemispheric approach $(n=13)$, including a unilateral low anterior interhemispheric approach or bifrontal interhemispheric approach, for high-positioned ACoA aneurysms with an aneurysm dome height $>15 \mathrm{~mm}$ and aneurysm neck height $>10 \mathrm{~mm}$ both measured from the level of the anterior clinoid process. The clinical and radiological data were reviewed to investigate the surgical results and risk factors of incomplete clipping.

Results : The pterional patient group showed a significantly higher incidence of incomplete clipping than the interhemispheric patient group ( $p=0.031$ ). Four patients (36.4\%) who underwent a pterional approach showed a postclipping aneurysm remnant, whereas all the patients who experienced an interhemispheric approach showed complete clipping. In one case, the aneurysm remnant was obliterated by coiling, while follow-up of the other three cases showed the remnants remained limited to the aneurysm base. A multivariate analysis revealed that a pterional approach for a large aneurysm with a diameter $>8 \mathrm{~mm}$ presented a statistically significant risk factor for incomplete clipping.

Conclusion : For high-positioned ACoA aneurysms with a dome height $>15 \mathrm{~mm}$ and neck height $>10 \mathrm{~mm}$ above the level of the anterior clinoid process, a large aneurysm with a diameter $>8 \mathrm{~mm}$ can be clipped more completely via an interhemispheric approach than via a pterional approach.

Key Words : Intracranial aneurysm · Anterior communicating aneurysm · High positioned.

\section{INTRODUCTION}

Most anterior communicating artery (ACoA) aneurysms are commonly clipped via a pterional approach or its modifications $^{18,23,26,31,33,36)}$. However, for high-positioned ACoA aneu- rysms, a pterional approach can require gyrus rectus resection and extreme retraction of the frontal lobe, resulting in a deep and narrow surgical corridor to the aneurysm ${ }^{14,16,18,23)}$. Conversely, a interhemispheric approach, including a unilateral low anterior interhemispheric approach or bifrontal inter-

- Received : July 24, 2020 •Revised : October 2, 2020 •Accepted : October 7, 2020

- Address for reprints : Jaechan Park

Department of Neurosurgery, Kyungpook National University Hospital, 130 Dongdeon-ro, Jung-gu, Daegu 41944, Korea

Tel : +82-53-200-5647, Fax : +82-53-423-0504, E-mail : jparkmd@hotmail.com or jparkneurosurgery@gmail.com, ORCID : https://orcid.org/0000-0001-7572-3260

This is an Open Access article distributed under the terms of the Creative Commons Attribution Non-Commercial License (http://creativecommons.org/licenses/by-nc/4.0) which permits unrestricted non-commercial use, distribution, and reproduction in any medium, provided the original work is properly cited. 
hemispheric approach, can be used to avoid brain transgression and extreme brain retraction, and achieve a wider surgical corridor ${ }^{5,711,15,19,35,37,39,40)}$.

The choice of a pterional-transsylvian or interhemispheric approach is usually based on the preference and experience of the attending surgeon, plus various modifications of pterional and interhemispheric approaches are available in technical notes and clinical studies. Yet, while literature includes reviews and discussions of both approaches, there has been no comparative study on the postoperative clipping status of high-positioned ACoA aneurysms ${ }^{4,13}$.

Accordingly, this retrospective study investigated the clipping status and clinical outcomes of a pterional approach in comparison with an interhemispheric approach for high-positioned ACoA aneurysms.

\section{MATERIALS AND METHODS}

This study was reviewed and approved by the Ethics Committee of Kyungpook National University Hospital (IRB No. 2019-11-050).

\section{Patient population}

A total of 192 patients underwent surgical treatment for a ruptured or unruptured ACoA aneurysm between January 2015 and December 2019 at the authors' institution. Among these patients, those with an aneurysm neck height (vertical distance from the level of the anterior clinoid process to the aneurysm neck) $>10 \mathrm{~mm}$ and aneurysm dome height (vertical distance from the level of the anterior clinoid process to the highest point of the aneurysm dome) $>15 \mathrm{~mm}$ were enrolled for this comparative study.

The inclusion criteria for this study were as follows : 1) diagnosis of an ACoA aneurysm based on preoperative digital subtraction angiography (DSA), 2) aneurysm neck height $>10$ $\mathrm{mm}$ from the level of the anterior clinoid process based on sagittal T2-weighted brain images or sagittal brain images reconstructed using preoperative computed tomography angiography (CTA), 3) aneurysm dome height $>15 \mathrm{~mm}$ from the level of the anterior clinoid process, 4) aneurysm dome projection in an anterior, superior, and posterior direction, 5) aneurysm treatment with surgical clipping via a pterional approach or interhemispheric approach, and 6) evaluation of the clipping state based on postoperative CTA. The exclusion criteria included a high-positioned ACoA aneurysm treated by endovascular coiling.

The treatment decision, surgical versus endovascular, was made based on the catheter angiography. Surgical treatment was favored over endovascular treatment for patients with the following situations : 1) wide-necked aneurysm requiring stent-assisted technology; 2) aneurysm with an arterial branch incorporated into the sac; and 3) difficult navigation of the microcatheter into the aneurysm, as long as the patients had no problems related to comorbidity or hemostasis ${ }^{3,10,21,25,27,28)}$.

\section{Surgical procedures}

A pterional or interhemispheric approach was performed for a high-positioned ACoA aneurysm, where the interhemispheric approach included a unilateral low anterior interhemispheric approach or bifrontal interhemispheric approach.

First, a pterional craniotomy, comprising a frontotemporal craniotomy and drilling the lesser wing of the sphenoid, facilitated a pterional-transsylvian approach (Fig. 1A). The bilateral

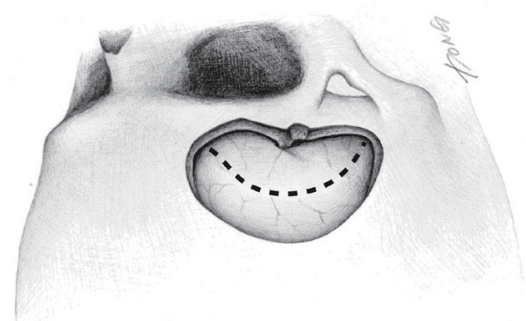

(A)

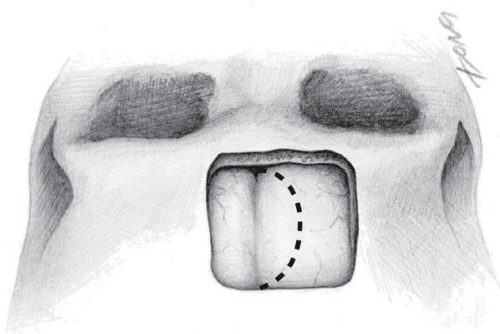

(B)

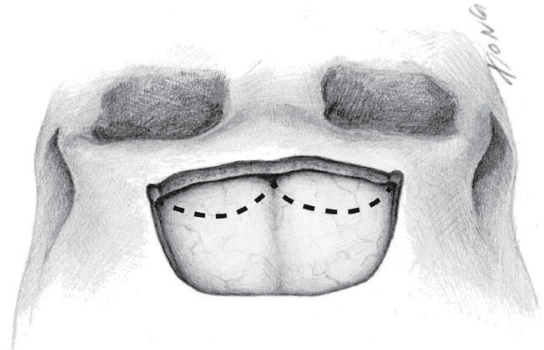

(C)

Fig. 1. Illustrations depicting the craniotomies for high-positioned anterior communicating artery aneurysms. A : Pterional approach. B : Unilateral low anterior interhemispheric approach. C : Subfrontal interhemispheric approach. Dotted lines show dural incision. 
A1 segments were exposed for proximal vascular control using subfrontal brain retraction. Subsequent gyrus rectus resection and entrance into the interhemispheric fissure through the pia of the medial hemisphere allowed access to the high-positioned ACoA aneurysm. Dissection of the ipsilateral olfactory tract can preserve the olfactory function and facilitate retraction of the frontal lobe when a retractor is applied between the dissected olfactory tract and the frontal lobe.

For superiorly-projecting ACoA aneurysms hiding the contralateral A2 segment, temporary clipping of the proximal vessel, peri-aneurysmal dissection, and aneurysm manipulation revealed any hidden arteries in the surgical blind spot. A clip trajectory, with the clip facing the anterolateral aspect of the aneurysm, was then used between the bilateral A2 segments.

Second, a bicoronal scalp incision and unilateral low anterior craniotomy facilitated a unilateral low anterior interhemispheric approach to a high-positioned ACoA aneurysm (Fig. 1B). The unilateral low anterior interhemispheric approach in the present study has been called a low anterior interhemispheric approach, unilateral anterior interhemispheric approach or anterior interhemispheric approach in literature $^{5,11,35,40)}$. The craniotomy side, left or right, was determined based on best possibility of preserving the parasagittal bridging veins. A C-shaped dural flap was formed along the superior sagittal sinus, allowing the superior sagittal sinus and falx to remain undisturbed. The interhemispheric fissure was then entered while avoiding the parasagittal bridging veins. Using retraction on the medial surface of the frontal lobe, the dissection was extended down into the interhemispheric fissure along the falx, with a dissecting trajectory almost along the floor of the anterior cranial fossa to reach the proximal A2 segment of the anterior cerebral artery (ACA) and then the ACoA complex.

Third, a bicoronal scalp incision and bifrontal craniotomy were used for a bifrontal interhemispheric approach (Fig. 1C). The bifrontal interhemispheric approach in the present study has been called an anterior interhemispheric approach or bifrontal interhemispheric approach in literature ${ }^{15,37)}$. The dura was incised along the anterior bone edge using a $\mathrm{W}$ shape to avoid damage to the bridging veins. The superior sagittal sinus was cut at its anterior end after ligation, while the falx cerebri was cut as far forward as possible. The crista galli was removed if it was large. Several arachnoid bands connecting the brain surface to the dura were cut. The olfactory tracts running parallel to the midline were then dissected from the orbital surface of the bilateral frontal lobes as far as the olfactory trigonal regions. This provided subfrontal access to the carotid cistern and optic nerve cistern. Such procedures resulted in gravity retraction of the frontal lobes. Opening the carotid cistern around the carotid terminus revealed the proximal Al segment of the ACA for early proximal vascular control. The posterior half of the subfrontal interhemispheric fissure behind the position of the crista galli was then dissected to reach the high-positioned ACoA aneurysm.

\section{Data collection}

The medical records were reviewed to obtain relevant clinical information, and all the radiological data used in this study were obtained using an electronic picture archiving and communication system. For all patients, the preoperative angiographic diagnosis was made using DSA, while the postoperative angiographic evaluation of the clipping state was performed using CTA.

The heights of the aneurysm dome and neck were measured using sagittal T2 weighted brain images or sagittal brain images reconstructed using the preoperative CTA

\section{Statistical analysis}

The statistical analyses were performed with the aid of commercially available statistics software (IBM SPSS version 19.0; SPSS, Inc., Chicago, IL, USA). Univariate and multivariate analyses were both performed to investigate the risk factors of incomplete clipping for a high-positioned ACoA aneurysm. To select the significant variables for inclusion in a binary logistic regression analysis, a Fisher's exact test was used for the categorical variables, including the sex, presentation with a subarachnoid hemorrhage (SAH), surgical approach, pterional approach for a high-positioned ACoA aneurysm with a diameter $>8 \mathrm{~mm}$, while a two-sample t-test and Mann-Whitney U test were used for the quantitative variables, including the patient age, aneurysm diameter, and aneurysm dome height and neck height above the level of the anterior clinoid process. To compare the clinical characteristics, radiological data, and aneurysmal clipping state between the pterional and interhemispheric patient groups, a Fisher's exact test was performed for the categorical variables (sex, presentation with SAH, and in- 
complete clipping), while a two sample t-test and MannWhitney $U$ test with and without a normality assumption were performed for the quantitative variables (age, aneurysm diameter, and aneurysm dome height and neck height above the level of the anterior clinoid process). The results were considered significant for probability values less than 0.05 .

\section{RESULTS}

\section{Patient characteristics}

The clinical and radiological characteristics of 24 patients who underwent surgical clipping for a high-positioned ACoA aneurysm are summarized in Table 1. The patient age ranged from 34 to 77 years (mean \pm standard deviation [SD], 57.0土
10.2), and 11 patients $(41.7 \%)$ were male. Ten patients $(41.7 \%)$ presented with a SAH due to a ruptured ACoA aneurysm, while the other patients presented with an incidental unruptured ACoA aneurysm.

The maximum diameter of the aneurysms ranged from 4.1 $\mathrm{mm}$ to $11.2 \mathrm{~mm}$ (mean $\pm \mathrm{SD}, 7.6 \pm 2.8$ ). Measured from the level of the anterior clinoid process, the aneurysm dome height ranged from $15.1 \mathrm{~mm}$ to $22.4 \mathrm{~mm}$ (mean $\pm \mathrm{SD}, 17.1 \pm 1.8$ ) and the aneurysm neck height ranged from $10.1 \mathrm{~mm}$ to $15.2 \mathrm{~mm}$ (mean \pm SD, 11.5 \pm 1.3 ). The high-positioned ACoA aneurysms were directed superiorly $(\mathrm{n}=14,58.3 \%)$ or anteriorly $(\mathrm{n}=10$, 41.7\%), with none directed inferiorly.

The surgical approaches applied to the patients were a pterional approach $(\mathrm{n}=11,45.8 \%)$ or interhemispheric approach $(n=13,54.2 \%)$ that included a unilateral low anterior inter-

Table 1. Demographic data and angiographic characteristics of 24 patients who underwent surgical treatment for high-positioned ACoA aneurysms

\begin{tabular}{lc}
\hline Characteristic & Value \\
\hline Age (years) & $57.0 \pm 10.2(34-77)$ \\
Male patients & $11(45.8)$ \\
Patients with SAH & $10(41.7)$ \\
Aneurysm diameter $(\mathrm{mm})$ & $7.6 \pm 2.8(4.1-11.2)$ \\
Height of aneurysm dome above anterior clinoid process $(\mathrm{mm})$ & $17.1 \pm 1.8(15.1-22.4)$ \\
Height of aneurysm neck above anterior clinoid process $(\mathrm{mm})$ & $11.5 \pm 1.3(10.1-15.2)$ \\
Aneurysm direction & $14(58.3)$ \\
$\quad$ Superior & $10(41.7)$ \\
Anterior & $0(0.0)$ \\
Inferior & $11(45.8)$ \\
Patients according to surgical approach & $13(54.2)$ \\
Pterional approach & 1 (nterhemispheric approach \\
\hline
\end{tabular}

Values are presented as mean \pm standard deviation (range) or number (\%). ACOA : anterior communicating artery, SAH : subarachnoid hemorrhage

Table 2. Clinical and angiographic characteristics of four patients with incomplete clipping

\begin{tabular}{|c|c|c|c|c|c|c|c|c|c|}
\hline $\begin{array}{l}\text { Case } \\
\text { No. }\end{array}$ & $\begin{array}{l}\text { Age (years), } \\
\text { sex }\end{array}$ & $\begin{array}{c}\text { Aneurysm } \\
\text { rupture status }\end{array}$ & $\begin{array}{c}\text { Aneurysm } \\
\text { diameter }(\mathrm{mm})\end{array}$ & $\begin{array}{l}\text { Aneurysm neck } \\
\text { diameter }(\mathrm{mm})\end{array}$ & $\begin{array}{l}\text { Aneurysm dome } \\
\text { height }(\mathrm{mm})\end{array}$ & $\begin{array}{l}\text { Aneurysm neck } \\
\text { height }(\mathrm{mm})\end{array}$ & $\begin{array}{l}\text { Aneurysm } \\
\text { direction }\end{array}$ & $\begin{array}{l}\text { Surgical } \\
\text { approach }\end{array}$ & $\mathrm{mRS}$ \\
\hline 1 & $34, M$ & Ruptured & 8.8 & 5.2 & 16.8 & 10.5 & Mainly superior & Pterional & 0 \\
\hline 2 & $66, F$ & Unruptured & 8.2 & 5.5 & 18.5 & 10.7 & Mainly superior & Pterional & 0 \\
\hline 3 & $63, F$ & Unruptured & 9.2 & 7.3 & 15.6 & 10.2 & $\begin{array}{l}\text { Anterior, } \\
\text { contralaterally }\end{array}$ & Pterional & 0 \\
\hline 4 & $52, \mathrm{M}$ & Ruptured & 9.1 & 6.9 & 18.2 & 13.2 & $\begin{array}{l}\text { Antero-superior, } \\
\text { contralaterally }\end{array}$ & Pterional & 0 \\
\hline
\end{tabular}

mRS : modified Rankin Scale, $M$ : male, $F$ : female 
hemispheric approach $(n=3,12.5 \%)$ or bifrontal interhemispheric approach $(\mathrm{n}=10,41.7 \%)$.

\section{Postclipping aneurysmal remnant}

Based on the postoperative CTA or DSA, incomplete aneurysm clipping with a remnant was observed in four patients (16.7\%), and the clinical and angiographic characteristics of these four patients are summarized in Table 2. All four patients had a high-positioned ACoA aneurysm with a diameter $>8 \mathrm{~mm}$ and underwent a pterional approach for clipping.

Case 1 with incomplete clipping was a 34 year-old male with a ruptured high-positioned ACoA aneurysm (Fig. 2A). The standard pterional approach provided a deep and narrow surgical field with inadequate exposure of the aneurysm,
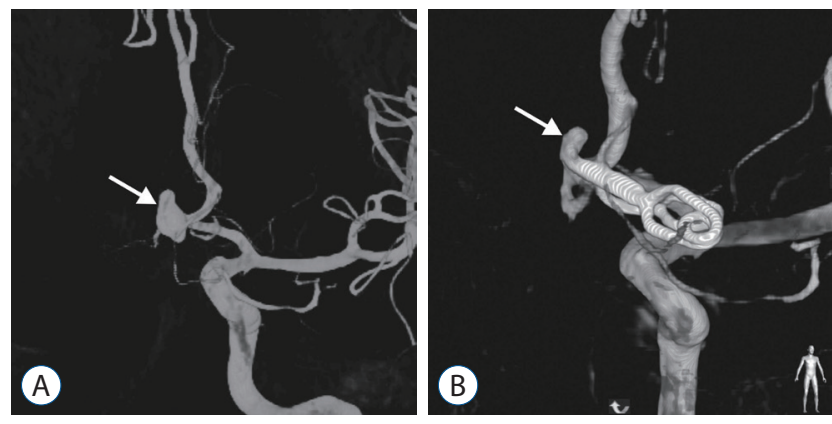

Fig. 2. Case 1 with incomplete clipping. A : DSA showing a ruptured high-positioned ACoA aneurysm (arrow) with a diameter of $8.8 \mathrm{~mm}$. B : Postoperative DSA showing the incompletely clipped ACoA aneurysm with a remnant (arrow). DSA : digital subtraction angiography, $A C O A$ : anterior communicating artery. which resulted in incomplete aneurysmal clipping due to the high-position of the aneurysm (aneurysm neck hight, 10.5 $\mathrm{mm}$; aneurysm dome height, $16.8 \mathrm{~mm}$ ), large size of the aneurysm (diameter, $8.8 \mathrm{~mm}$ ), and considerable brain swelling. The postoperative DSA revealed that the blades of the aneurysm clip had not completely crossed the entire neck of the aneurysm (Fig. 2B). The aneurysm remnant was uneventfully obliterated using endovascular coiling.

For the other three cases with incomplete clipping, the patients underwent a standard pterional craniotomy for a ruptured ACoA aneurysm or mini-pterional craniotomy for an unruptured ACoA aneurysm. Yet, all three ACoA aneurysms were more than $8 \mathrm{~mm}$ in diameter. Plus, the aneurysm neck height ranged from $10.2 \mathrm{~mm}$ to $13.2 \mathrm{~mm}$ and the aneurysm dome height ranged from $15.6 \mathrm{~mm}$ to $18.5 \mathrm{~mm}$. As the aneurysmal remnants were limited to the aneurysm base, the decision was taken to avoid reoperation, and no interval changes were found on the follow-up CTA over an average of 5 years.

\section{Risk factors for incomplete clipping of high-posi- tioned ACoA aneurysms}

The risk factors of incomplete clipping for a high-positioned ACoA aneurysm were investigated. In the univariate analysis (Table 3), a pterional approach was significantly associated with incomplete clipping ( $p=0.031$ ). Although, the aneurysm diameter failed to reach statistical significance, it still showed a borderlines significance $(p=0.081)$. Thus, a pterional approach for a large aneurysm with a diameter $>8 \mathrm{~mm}$ was ex-

Table 3. Univariate analysis results of risk factors for incomplete clipping in patients with a high-positioned ACoA aneurysm

\begin{tabular}{|c|c|c|c|}
\hline Variable & Incomplete clipping $(n=4)$ & Complete clipping $(n=20)$ & $p$-value \\
\hline Age (years) & $53.8 \pm 14.5$ & $57.6 \pm 9.5$ & $0.502^{\dagger}$ \\
\hline Male & $2(50.0)$ & $9(45.0)$ & $1.000^{\S}$ \\
\hline $\mathrm{SAH}$ & $2(50.0)$ & $8(40.0)$ & $1.000^{\S}$ \\
\hline Aneurysm diameter (mm) & $8.8 \pm 0.5$ & $7.3 \pm 3.0$ & $0.081^{\ddagger}$ \\
\hline Height of aneurysm neck above anterior clinoid process (mm) & $11.1 \pm 1.4$ & $11.5 \pm 1.3$ & $0.260^{\ddagger}$ \\
\hline Height of aneurysm dome above anterior clinoid process (mm) & $17.3 \pm 1.3$ & $17.1 \pm 1.9$ & $0.682^{\ddagger}$ \\
\hline Surgical approach & & & $0.031^{*, \$}$ \\
\hline Pterional appraoch & $4(100.0)$ & $7(35.0)$ & \\
\hline Interhemispheric approach & $0(0.0)$ & $13(100.0)$ & \\
\hline Pterional approach \& aneurysm diameter $>8 \mathrm{~mm}$ & $4(100.0)$ & $0(0.0)$ & $0.001^{*, \$}$ \\
\hline
\end{tabular}

Values are presented as mean \pm standard deviation or number (\%). * Indicates statistical significance. ${ }^{\dagger}$ Two sample t-test with normality assumption. ${ }^{\ddagger}$ Mann-Whitney U-test without normality assumption. ${ }^{\S}$ Fisher's exact test. ACOA : anterior communicating artery, SAH : subarachnoid hemorrhage 
amined as a risk factor. It was significantly associated with incomplete clipping ( $p=0.001)$.

When further investigated as a risk factor using a multivariate analysis with a binary logistic regression analysis, a pterional approach for a large aneurysm with a diameter $>8 \mathrm{~mm}$ was significantly associated with incomplete clipping in cases of a high-positioned ACoA aneurysm (odds ratio, 121.0; 95\% confidence interval, 6.7-2188.2; $p=0.001)$.

\section{Pterional approach versus interhemispheric ap- proach}

The patients who underwent a pterional approach $(n=11)$ versus an interhemispheric approach $(n=13)$ were compared regarding their clinical characteristics, radiological data, and clipping state (Table 4). Both groups were comparable without any between-group difference for patient age, sex, presence of a SAH, aneurysm diameter, and aneurysm dome height and aneurysm neck height measured from the level of the anterior clinoid process.

Notwithstanding, the pterional patient group showed a significantly higher incidence of incomplete clipping than the interhemispheric patient group ( $p=0.031$ ). Four patients $(36.4 \%)$ who underwent a pterional approach showed a postclipping aneurysm remnant, whereas all the patients who experienced an interhemispheric approach showed complete clipping of the high-positioned ACoA aneurysms.

In particular, incomplete clipping after a pterional approach was observed in cases of a large aneurysm with a diameter $>8$ $\mathrm{mm}$, where a postclipping aneurysm remnant was observed in four of the five large aneurysm cases with a diameter $>8 \mathrm{~mm}$ in the pterional patient group, while no incomplete clipping was observed among the four large aneurysm cases with a diameter $>8 \mathrm{~mm}$ in the interhemispheric patient group.

No between-group difference was identified for patients with a good clinical outcome (modified Rankin Scale [mRS], 0 or 1 ) or cognitive dysfunction. After excluding two patients with World Federation of Neurosurgical Societies (WFNS) grade 5 due to a ruptured aneurysm, all the remaining patients presented with a ruptured aneurysm and good WFNS grade (1 or 2) or unruptured ACoA aneurysm, resulting in favorable clinical outcomes with a mRS score 0 or 1 . Mild cognitive dysfunction with memory impairment was reported for five patients (45.5\%) from the pterional group and three patient $(23.1 \%)$ from the interhemispheric group.

\section{DISCUSSION}

This retrospective study proposed that an interhemispheric approach provides better access to a high-positioned ACoA aneurysm for complete clipping than a pterional approach. In particular, this was confirmed in cases of a large, high-positioned ACoA aneurysm with a diameter $>8 \mathrm{~mm}$.

There is no clear consensus on the definition of a high-positioned ACoA aneurysm. Kim et al. ${ }^{22)}$ defined a high-positioned ACoA aneurysm as located higher than $10 \mathrm{~mm}$ above

Table 4. Comparison of patients who underwent a pterional approach or interhemispheric approach for high-positioned ACoA aneurysms

\begin{tabular}{|c|c|c|c|}
\hline Variable & $\begin{array}{l}\text { Pterional approach } \\
\qquad(n=11)\end{array}$ & $\begin{array}{l}\text { Interhemispheric approach } \\
\qquad(\mathrm{n}=13)\end{array}$ & $p$-value \\
\hline Age (years) & $56.3 \pm 11.6(34-77)$ & $57.5 \pm 9.2(44-68)$ & $0.769^{\dagger}$ \\
\hline Male patients & $5(45.5)$ & $6(46.2)$ & $0.973^{\S}$ \\
\hline Patients with SAH & $5(45.5)$ & $5(38.5)$ & $0.729^{\S}$ \\
\hline Aneurysm diameter (mm) & $7.2 \pm 2.1(4.1-10.1)$ & $8.0 \pm 3.3(4.2-17.0)$ & $0.750^{\ddagger}$ \\
\hline Height of aneurysm dome above anterior clinoid process (mm) & $17.0 \pm 1.4(15.4-19.1)$ & $17.2 \pm 2.0(15.1-22.4)$ & $0.451^{\ddagger}$ \\
\hline Height of aneurysm neck above anterior clinoid process (mm) & $11.1 \pm 1.0(10.1-13.2)$ & $11.8 \pm 1.5(10.4-15.2)$ & $0.270^{\ddagger}$ \\
\hline Patients with incomplete clipping & $4(36.4)$ & $0(0.0)$ & $0.031^{*, \S}$ \\
\hline Patients with mRS 0-1 & $10(90.9)$ & $12(92.3)$ & $1.000^{\S}$ \\
\hline Patients with cognitive dysfunction & $5(45.5)$ & $3(23.1)$ & $0.390^{\S}$ \\
\hline
\end{tabular}

Values are presented as mean \pm standard deviation (range) or number (\%). *Indicates statistical significance. ${ }^{\dagger}$ Two sample t-test with normality assumption. ${ }^{\ddagger}$ Mann-Whitney U-test without normality assumption. ${ }^{\S}$ Fisher's exact test. ACoA : anterior communicating artery, SAH : subarachnoid hemorrhage, mRS : modified Rankin Scale 
the anterior clinoid process, while Diraz et al. ${ }^{4)}$ defined it as an ACoA aneurysm with a neck height of $13 \mathrm{~mm}$ or more above the anterior clinoid process. The position of an ACoA aneurysm can be measured from the level of the anterior clinoid process to various points on the aneurysm, such as the lowest point, neck portion, and highest point of the aneurysm. When describing the position of an ACoA aneurysm using the distance from the level of the anterior clinoid process to the aneurysm neck, the real aneurysm position can differ according to the direction of the aneurysm dome. A superior-directing ACoA aneurysm is invariably located higher than an inferiordirecting ACoA aneurysm, even with the same neck height. Moreover, when using the distance to the lowest point of the ACoA aneurysm to define a high-positioned ACoA aneurysm, the real aneurysm position will differ according to the aneurysm size. Here, a larger ACoA aneurysm is invariably located higher than a smaller ACoA aneurysm, even with the same position of the lowest point of the ACoA aneurysm. Accordingly, this comparative study was performed using a definition of a high-positioned ACoA aneurysm which comprises of an aneurysm neck height $>10 \mathrm{~mm}$ and aneurysm dome height $>15 \mathrm{~mm}$ measured from the level of the anterior clinoid process.

Instead of using a pterional approach for a high-positioned ACoA aneurysm, an interhemispheric approach has been proposed and already discussed in literature. However, there has been no comparative study of these two surgical approaches that includes the postoperative clipping status and clinical outcomes. Thus, to the best our knowledge, this is the first comparative study demonstrating a better clipping status resulting from an interhemispheric approach for high-positioned ACoA aneurysms.

A pterional approach is widely accepted as the standard procedure for ACoA aneurysms, as its advantages include technical ease, familiarity since it is commonly applied for many anterior circulation aneurysms, and early achievement of proximal vascular control at the Al segment of the ACA. However, the disadvantages include brain transgression, severe brain retraction, and narrow surgical exposure of the lesion for a high-positioned ACoA aneurysm, despite introduction of an easy dissection technique of an interhemispheric fissure by Kashimura et $\mathrm{al}^{14,17,18,22)}$. For surgical access to a high-positioned ACoA aneurysms, the brain transgression can include the septal area above the gyrus rectus, which can damage the cholinergic projection from the basal forebrain to the hippocampus and entire cerebral cortex ${ }^{2,38)}$.

While partial resection of the gyrus rectus in common ACoA aneurysm surgery has been shown not to affect the surgical results or quality of life ${ }^{14,16,18}$, the effect of brain transgression on postoperative cognitive function in a pterional approach for a high-positioned ACoA aneurysm has not been fully investigated. Very few clinical studies have focused on patients with a high-positioned ACoA aneurysm, and most surgical results have only used simple outcome scales, such as the Glasgow outcome scale. Meanwhile, cognitive impairment, including memory impairment, confabulation, and personality changes, is well known to occur in some patients following the rupture of an ACoA aneurysm ${ }^{1,6,16,26,29,32,33,36)}$. An aneurysmal intracerebral hemorrhage damaging the basal forebrain is considered to be more causative than a diffuse SAH. In the present study, the incidence of postoperative memory impairment was higher in the pterional patient group than in the interhemispheric patient group. However, the between-group difference did not quite reach statistical significance ( $p=0.135$ ). As the present study only investigated cognitive impairment based on patient feedback in the postoperative follow-up, a neuropsychological test of all patients would present more reliable results.

A unilateral low anterior interhemispheric approach does not require brain transgression, dissection of the olfactory tract, and division of the superior sagittal sinus ${ }^{5,11,20,38)}$. However, the disadvantages include the following. First, some frontal parasagittal bridging veins can inevitably be sacrificed, as the dissecting trajectory is almost fixed along the floor of the anterior cranial fossa ${ }^{20)}$. This can disturb the venous blood flow through the frontal ascending veins, while the additional brain retraction increases the risk of venous infarction ${ }^{30,34)}$. Second, the extent of the interhemispheric dissection is approximately twice that of a bifrontal interhemispheric approach $^{8)}$. The cortical surfaces of the medial frontal lobes can be tightly opposed and adherent, making interhemispheric dissection sometimes difficult and laborious. Moreover, agerelated brain atrophy can increase the cerebrospinal fluid volume in the sylvian fissure (frontotemporal atrophy), sulci (cortical atrophy), and ventricles (central cerebral atrophy), making dissection of the sylvian fissure can be easier than interhemispheric dissection ${ }^{12,24,26)}$. Third, early proximal vascular control is not possible in the unilateral low anterior interhemispheric approach ${ }^{5}$. The parent artery distal to the 
aneurysm, the A2 segment of the ACA, is generally reached first in the interhemispheric fissure, followed by careful dissection past the aneurysm to the proximal parent artery. Thus, cases of a ruptured aneurysm can become troublesome due to an intraoperative premature rupture.

Meanwhile, when using a bifrontal interhemispheric approach for a high-positioned ACoA aneurysm, the risk of venous infarction is extremely low as the parasagittal bridging veins are commonly preserved ${ }^{7,39)}$. Less interhemispheric dissection is required to reach the lesion than with a unilateral low anterior interhemispheric approach ${ }^{8)}$. Subfrontal access to the carotid cistern allows early proximal vascular control at the proximal A1 segment of the $\mathrm{ACA}^{15,37)}$. If an in situ side-toside bypass is required using bilateral pericallosal arteries during surgery for a high-positioned ACoA aneurysm, a bifrontal interhemispheric approach is most appropriate, as it exposes the bilateral pericallosal arteries with a shallower surgical field than a unilateral low anterior interhemispheric approach ${ }^{15)}$. Yet, the disadvantages of this surgical approach include the need to dissect the bilateral olfactory tracts and frequent transection of the frontal sinus ${ }^{37)}$.

Dome projection of an ACoA aneurysm also affects the choice of a surgical approach. Inferior-projecting ACoA aneurysms are easily accessible via a pterional approach, while superior-directing ACoA aneurysms are suitable for an interhemispheric approach. However, in the present case series of a high-positioned ACoA aneurysm, all aneurysms projected anteriorly or superiorly with no case of inferior projection. Therefore, this comparative study was not performed for the analysis of aneurysm projection.

The current study has several limitations. First, it is based on a retrospective review of data from a single institution. Second, while this study included common surgical approaches for a high-positioned ACoA aneurysm, other modified approaches, such as an orbitozygomatic approach and basal interhemispheric approach, were not considered ${ }^{8,9}$. Third, this study was not a prospective randomized study. However, the selection bias was minimal. When deciding the surgical approach for a high-positioned ACoA aneurysm, a pterional approach was performed until 2016 and an interhemispheric approach has been preferred since 2017. It explains the absence of any statistically significant between-group difference in the aneurysm diameter, neck height, and dome height. Fourth, future prospective, multi-center studies including a clipping status evaluation and neuropsychological test are warranted.

\section{CONCLUSION}

Our results demonstrate that an interhemispheric approach, including a unilateral low anterior interhemispheric approach and bifrontal interhemispheric approach, can achieve a better clipping status than a pterional approach for large (diameter $>8 \mathrm{~mm}$ ), high-positioned (aneurysm neck height $>10 \mathrm{~mm}$ and aneurysm dome height $>15 \mathrm{~mm}$ measured from the level of the anterior clinoid process) ACoA aneurysms.

\section{CONFLICTS OF INTEREST}

Jaechan Park has been editorial board of JKNS since November 2014. He was not involved in the review process of this original article. No other potential conflict of interest relevant to this article was reported.

\section{INFORMED CONSENT}

Informed consent was obtained from all individual participants included in this study.

\section{AUTHOR CONTRIBUTIONS}

\author{
Conceptualization : JP \\ Data curation : $\mathrm{MK}, \mathrm{BJK}$ \\ Formal analysis : $\mathrm{MK}, \mathrm{BJK}$ \\ Funding acquisition : JP \\ Methodology : WS \\ Project administration : WS \\ Visualization : WS \\ Writing - original draft : JP, MK \\ Writing - review \& editing : JP
}

\section{ORCID}

Myungsoo Kim https://orcid.org/0000-0003-2764-2508 
Byoung-Joon Kim https://orcid.org/0000-0002-9375-1799

Wonsoo Son

https://orcid.org/0000-0003-1148-1404

Jaechan Park

\section{References}

1. Alexander MP, Freedman $M$ : Amnesia after anterior communicating artery aneurysm rupture. Neurology $34:$ 752-757, 1984

2. Benke T, Köylü B, Delazer M, Trinka E, Kemmler G : Cholinergic treatment of amnesia following basal forebrain lesion due to aneurysm rupture--an open-label pilot study. Eur J Neurol 12 : 791-796, 2005

3. Birknes JK, Hwang SK, Pandey AS, Cockroft K, Dyer AM, Benitez RP, et al. : Feasibility and limitations of endovascular coil embolization of anterior communicating artery aneurysms: morphological considerations. Neurosurgery 59 : 43-52; discussion 43-52, 2006

4. Diraz A, Kobayashi S, Toriyama T, Ohsawa M, Hokama M, Kitazama K : Surgical approaches to the anterior communicating artery aneurysm and their results. Neurol Res $15: 273-280,1993$

5. El-Noamany H, Nakagawa F, Hongo K, Kakizawa Y, Kobayashi S : Low anterior interhemispheric approach--a narrow corridor to aneurysms of the anterior communicating artery. Acta Neurochir (Wien) 143 : 885-891, 2001

6. Fontanella MM, Bergamasco L, Perozzo P, Priano L, Vighetti S, Griva F, et al. : Neuropsychological and neurophysiological evaluation after anterior communicating artery $(\mathrm{ACO} A)$ aneurysm surgery. J Neurosurg Sci 44 : 61-66; discussion 66-67, 2000

7. Fujitsu K, Sekino T, Sakata K, Kawasaki T : Basal interfalcine approach through a frontal sinusotomy with vein and nerve preservation. Technical note. J Neurosurg 80 : 575-579, 1994

8. Fujiwara $H$, Yasui $N$, Nathal-Vera E, Suzuki A : Anosmia after anterior communicating artery aneurysm surgery: comparison between the anterior interhemispheric and basal interhemispheric approaches. Neurosurgery $38: 325-328,1996$

9. Gonzalez LF, Crawford NR, Horgan MA, Deshmukh P, Zabramski JM, Spetzler RF : Working area and angle of attack in three cranial base approaches: pterional, orbitozygomatic, and maxillary extension of the orbitozygomatic approach. Neurosurgery 50 : 550-555; discussion 555-557, 2002

10. Guglielmi G, Viñuela F, Duckwiler G, Jahan R, Cotroneo E, Gigli R : Endovascular treatment of 306 anterior communicating artery aneurysms: overall, perioperative results. J Neurosurg $110: 874-879,2009$

11. Hayashi N, Sato H, Akioka N, Kurosaki K, Hori S, Endo S : Unilateral anterior interhemispheric approach for anterior communicating artery aneurysms with horizontal head position--technical note. Neurol Med Chir (Tokyo) 51 : 160-163, 2011

12. Hedman AM, van Haren NE, Schnack HG, Kahn RS, Hulshoff Pol HE : Human brain changes across the life span: a review of 56 longitudinal magnetic resonance imaging studies. Hum Brain Mapp 33 : 19872002, 2012

13. Hernesniemi J, Dashti $R$, Lehecka $M$, Niemelä M, Rinne J, Lehto $H$, et al. : Microneurosurgical management of anterior communicating artery aneurysms. Surg Neurol 70 : 8-28; discussion 29, 2008

14. Horikoshi T, Nukui $H$, Mitsuka $S$, Kaneko $M$ : Partial resection of the gyrus rectus in pterional approach to anterior communicating artery aneurysms. Neurol Med Chir (Tokyo) 32 : 136-139, 1992

15. Ito $Z$ : The microsurgical anterior interhemispheric approach suitably applied to ruptured aneurysms of the anterior communicating artery in the acute stage. Acta Neurochir (Wien) $63:$ 85-99, 1982

16. Joo MS, Park DS, Moon CT, Chun YI, Song SW, Roh HG : Relationship between gyrus rectus resection and cognitive impairment after surgery for ruptured anterior communicating artery aneurysms. J Cerebrovasc Endovasc Neurosurg 18 : 223-228, 2016

17. Kashimura H, Kubo Y, Ogasawara K, Kakino S, Yoshida K, Ogawa A : Easy dissection of the interhemispheric fissure for treatment of the anterior communicating artery aneurysm by the pterional approach. World Neurosurg $73: 688-690,2010$

18. Kempe $L G$, VanderArk $G D$ : Anterior communicating artery aneurysms. Gyrus rectus approach. Neurochirurgia (Stuttg) 14 : 63-70, 1971

19. Keogh AJ, Sharma RR, Vanner GK : The anterior interhemispheric trephine approach to anterior midline aneurysms: results of treatment in 72 consecutive patients. Br J Neurosurg 7 : 5-12, 1993

20. Kikuchi K, Watanabe K: Modified bifrontal interhemispheric approach to aneurysms of the anterior communicating artery with the use of a trephine craniotomy. A review of personal experience with 25 cases. Acta Neurochir (Wien) $125:$ 127-131, 1993

21. Kim BM, Park SI, Kim DJ, Kim DI, Suh SH, Kwon TH, et al. : Endovascular coil embolization of aneurysms with a branch incorporated into the sac. AJNR Am J Neuroradiol 31 : 145-151, 2010

22. Kim H, Kim TS, Joo SP, Moon HS : Pterional-subolfactory approach for treatment of high positioned anterior communicating artery aneurysms.

J Cerebrovasc Endovasc Neurosurg 15 : 177-183, 2013

23. Lawton MT : Seven Aneurysms: Tenets and Techniques for Clipping. New York : Thieme Medical Publishers, Inc., 2011, pp94-120

24. Long $X$, Liao W, Jiang C, Liang D, Qiu B, Zhang L : Healthy aging: an automatic analysis of global and regional morphological alterations of human brain. Acad Radiol 19 : 785-793, 2012

25. Lubicz B, Lefranc F, Levivier M, Dewitte O, Pirotte B, Brotchi J, et al. : Endovascular treatment of intracranial aneurysms with a branch arising from the sac. AJNR Am J Neuroradiol 27 : 142-147, 2006

26. Mavaddat N, Sahakian BJ, Hutchinson PJ, Kirkpatrick PJ : Cognition following subarachnoid hemorrhage from anterior communicating artery aneurysm: relation to timing of surgery. J Neurosurg 91 : 402-407, 1999

27. Moret J, Pierot L, Boulin A, Castaings L, Rey A : Endovascular treatment of anterior communicating artery aneurysms using Guglielmi detachable coils. Neuroradiology $38:$ : 800-805, 1996

28. Murayama Y, Nien YL, Duckwiler G, Gobin YP, Jahan R, Frazee J, et al. : Guglielmi detachable coil embolization of cerebral aneurysms: 11 years' experience. J Neurosurg 98 : 959-966, 2003

29. O'Connor MG, Lafleche GM : Retrograde amnesia in patients with rup- 
ture and surgical repair of anterior communicating artery aneurysms. J Int Neuropsychol Soc $10: 221-229,2004$

30. Park J, Hamm I : Anterior interhemispheric approach for distal anterior cerebral artery aneurysm surgery: preoperative analysis of the venous anatomy can help to avoid venous infarction. Acta Neurochir 146 : 973-977, 2004

31. Park J, Son W, Goh DH, Kang DH, Lee J, Shin IH : Height of aneurysm neck and estimated extent of brain retraction: powerful predictors of olfactory dysfunction after surgery for unruptured anterior communicating artery aneurysms. J Neurosurg 124 : 720-725, 2016

32. Proust $F$, Martinaud $O$, Gérardin $E$, Derrey $S$, Levèque $S$, Bioux $S$, et al. : Quality of life and brain damage after microsurgical clip occlusion or endovascular coil embolization for ruptured anterior communicating artery aneurysms: neuropsychological assessment. J Neurosurg 110 : 19-29, 2009

33. Ravnik J, Starovasnik B, Sesok S, Pirtosek Z, Svigelj V, Bunc G, et al. : Long-term cognitive deficits in patients with good outcomes after aneurysmal subarachnoid hemorrhage from anterior communicating artery. Croat Med J 47 : 253-263, 2006

34. Sindou M, Auque I : The intracranial venous system as a neurosurgeon's perspective in Cohadon F (ed) : Advances and Technical Standards in Neurosurgery. New York : Springer, 2000, Vol 26, pp131-216

35. Srour A, el Tantawi AM, Khouja N, Zouaoui A, Lassau JP, Philippon J, et al. : Neurosurgical anatomy of the anterior interhemispheric approach for aneurysms of the anterior communicating artery (26.6.92). Surg Radiol Anat 16 : 117-119, 1994

36. Stenhouse LM, Knight RG, Longmore BE, Bishara SN : Long-term cognitive deficits in patients after surgery on aneurysms of the anterior communicating artery. J Neurol Neurosurg Psychiatry 54 : 909-914, 1991

37. Suzuki J, Mizoi K, Yoshimoto T : Bifrontal interhemispheric approach to aneurysms of the anterior communicating artery. J Neurosurg 64 : 183-190, 1986

38. Wright RA, Boeve BF, Malec JF : Amnesia after basal forebrain damage due to anterior communicating artery aneurysm rupture. J Clin Neurosci 6 : 511-515, 1999

39. Yasui N, Nathal E, Fujiwara H, Suzuki A : The basal interhemispheric approach for acute anterior communicating aneurysms. Acta Neurochir (Wien) $118:$ 91-97, 1992

40. Yeh $\mathrm{H}, \mathrm{Tew} \mathrm{JM} \mathrm{Jr}$ : Anterior interhemispheric approach to aneurysms of the anterior communicating artery. Surg Neurol 23 : 98-100, 1985 